\title{
Monitoring radon emission anomalies at Stromboli Island as a tracer of eruptive events and "near field" earthquakes
}

\author{
G. Gervino ${ }^{1}$, A. Lavagno ${ }^{2}$, M. Laiolo $^{3}$, C. Cigolini $^{3}$, \\ D. Coppola ${ }^{3}$ and L. Periale ${ }^{4}$ \\ ${ }^{1}$ Dipartimento di Fisica Sperimentale di Torino, Italy \\ ${ }^{2}$ Dipartimento di Fisica, Politecnico di Torino, Italy \\ 3 DSMP, Università di Torino, Italy \\ ${ }^{4}$ IFSI-INAF, Sezione di Torino, Italy
}

\begin{abstract}
Radon emission from soil at Stromboli Island has been monitored since 2002 utilizing a network of 25 stations and exposing two kinds of detectors: E-PERM and calibrated track-etches (LR115). We present and discuss the data from 2002 to 2007, thus including the last two major eruptive cycles. Earthquake-volcano interactions were detected providing evidence that radon emissions are somehow related to the occurrence of regional earthquakes. Single deep earthquakes related to active subduction, such as Salina event $\left(\mathrm{M}_{\mathrm{L}}=5.1\right)$ of May 5, 2004, may be capable of increasing the ascent of geothermal fluids due to the passage of seismic waves. In addition, we observed major eruptions at Stromboli were preceded by anomalies that occurred at three summit stations that reached values above $20000 \mathrm{~Bq} \mathrm{~m}^{-3}$ : this is considered an anomalous value and could be regarded, under particular environmental conditions, as a potential precursory signal of a change in volcanic activity.
\end{abstract}

This is an Open Access article distributed under the terms of the Creative Commons Attribution License 2.0, which permits unrestricted use, distribution, and reproduction in any medium, provided the original work is properly cited. 

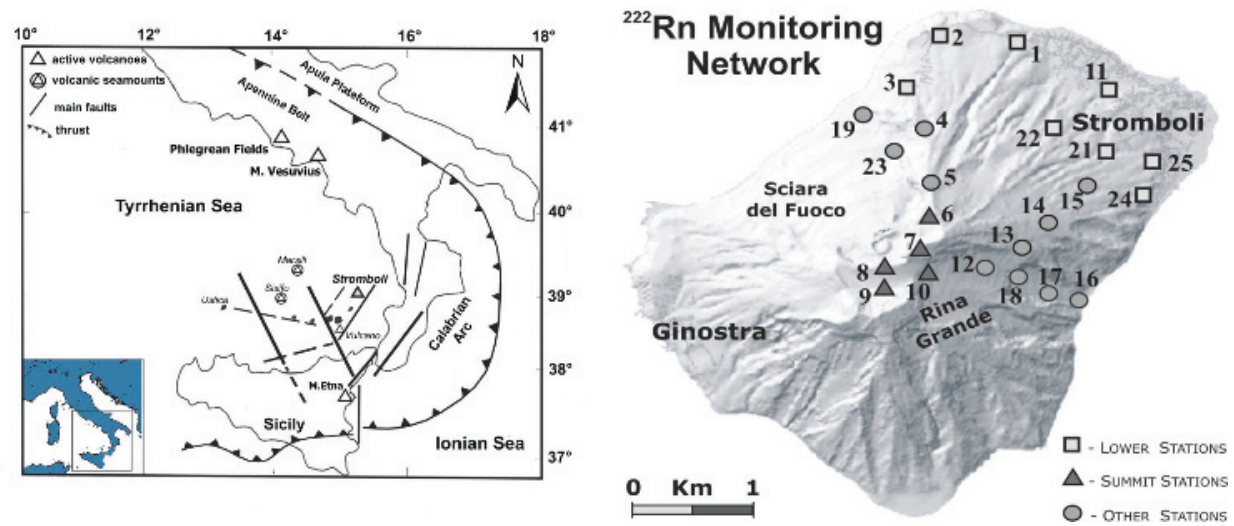

Figure 1: Location of the Stromboli island in the Southern Tyrrhenian Sea (left) and the Radon Network on the NE sector of the island installed in May 2002.

\section{Introduction}

Radon survey at Stromboli Volcano was systematically performed by a network of 21 stations from May 2002 to June 2007. The investigated sectors are the NE part of the cone (see fig. 1) with particular attention to the summit area that surround the active craters terrace. We hereby present a synthesis of our previous works.

Data were collected by using two different types of detectors: E-PERM electretes, exposed from 1 to 4 days (thus increasing the possibilities of correlating radon emissions with the variations in volcanic activity) and track-etch detectors (LR115, calibrated according to [1]) that were exposed from 14 to 40 days. All radon detectors were placed in PVC tubes $1 \mathrm{~m}$ long and $12 \mathrm{~cm}$ in diameter (isolated by a cap) and inserted into the soil down to a depth of about $60 \mathrm{~cm}$. In particular, the effects of daily temperature variations and soil humidity on radon emissions are minimized, at least for the LR115 detectors since they give an integrated measurement over a rather long exposure time (see ref. [1]). The contemporary use of these two experimental techniques allowed us to decode short term variations in volcanic activity as well as to track monthly average emissions affected by seasonal variations linked to average temperature and soil humidity.

Radon gas is mainly represented by the ${ }^{222} \mathrm{Rn}$ isotope (with a half-life of 3.82 days) that is an alpha emitter produced from the uranium decay chain. Investigation on spatial radon measurements is largely employed in many geological environments and can be a useful tool to track hidden structures [2]. Moreover, marked radon variations have been regarded as 


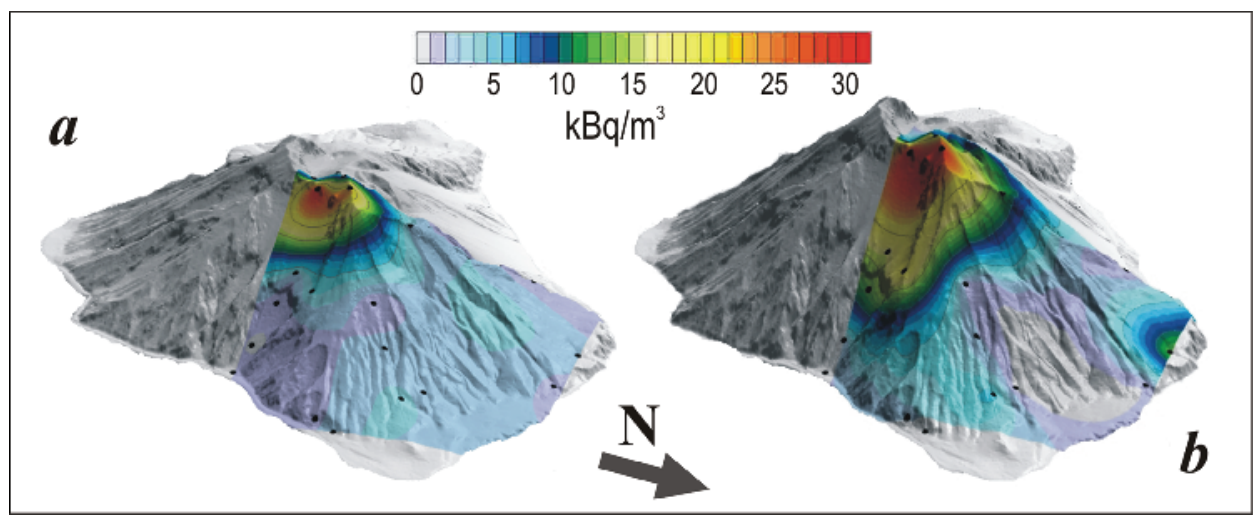

Figure 2: Average radon emission on the 21 sites of the network by using EPERM electrets (a); and measurements acquired during the last effusive event (b).

possible precursors of earthquakes and volcanic eruptions [3,4]. Soil radon anomalies have been observed before, during and after the onset of major seismic events, but positive anomalies in radon emissions have also been associated with changes in volcanic activity at Stromboli [5] and volcanicallyrelated earthquakes at Summa-Vesuvio [6].

By using the above alpha particles detection technique, radon can be monitored easily even when it is in extremely low concentrations. It may be used as a tracer to investigate the movement of geothermal fluids as well. Therefore, radon emission data were analysed to infer the temperature distribution of the deep hydrothermal system at Stromboli [7]. Moreover, radon anomalies were used to map the geometry of a hidden fault at Mount Etna [2]. Volcanic activity at Stromboli Volcano is characterized by a continuous and mild explosive activity, with eruptions of ashes, lapilli, scoriae and bombs that are ejected at the active summit vents. This typical and persistent activity may be periodically replaced by lava effusions, major explosions and paroxysms.

\section{Radon measurements}

In fig. 2 it is shown a summary of radon emission on 3D topographic DEM images on the NE sector of Stromboli Island related to the whole 2002-2007 survey data set (fig. 2a) and during the last major eruptive cycle (FebruaryMarch 2007 (fig. 2b). Black circles in figures indicate measurements sites. According to fig. 2a a general positive correlation between ${ }^{222} \mathrm{Rn}$ emissions and altitude can be observed: radon emissions increase their values towards 
the crater area where they reach their maxima (see also ref. [5]). By mid December 2002 three summit stations showed Rn emissions higher than $20000 \mathrm{~Bq} \mathrm{~m}^{-3}$ (i.e., 12 days befor the onset of lava effusion) with most stations recording values well below $10000 \mathrm{~Bq} \mathrm{~m}^{-3}$. Figure $2 \mathrm{~b}$ clearly shows that the higher radon activities during the last effusive cycle (from February 27 to April 2, 2007) were observed in the crater area as expected. These observations are also consistent with the model described in ref. [9]. According to this model, obtained by coupling Fick's second law and the Norton-Cathles equation (see ref. [7]) to a finite difference numerical method, the temperature distribution and the fluid flow rate are evaluated, showing that the gas flow is concentrated in the porous medium surrounding the conduit. Here, about $80 \%( \pm 10 \%)$ of the total fluid mass is flowing nearly parallel to the magma conduit and is realized in the crater area affecting a zone about $300 \mathrm{~m}$ away from the active vents. In the other sectors of the volcano, the fluid flow rate is estimated to be systematically below $10 \%$ of the maximum computed flow rate estimated at the summit. Only at one single station, located at the base of the cone (station 2), radon emissions reached values in the range of those recorded at the summit stations. In this case, we may ascribe this "anomaly" to the extension of the active hydrothermal system which is controlling fluid circulation along the fractures of volcanic edifice (located in the $\mathrm{NE}$ sector of the cone). Local anomalous values in radon emissions recorded at Station 2, positioned at the lower edge of Sciara del Fuoco, are thus related to degassing processes that occur along the lower, mostly submerged portion of the hydrothermal system that was involved in the activation of the sub-marine slumping that generated a tsunami on December 30, 2002. One of the anomalies is visible in fig. $2 \mathrm{~b}$, where the data are collected just during the development of the effusive phase. However, anomalies of this type seem to be associated with lava effusions and/or local earthquakes (see below) that affect the fracture network of the porous medium and contribute to a higher fluid release to the surface. In this framework, radon emissions are viewed as a relative witness of the total fluid activity in this volcanic domain.

Particular emphasis needs to be given to the tectonically-induced "Salina" seismic event on May 5, $2004\left(\mathrm{M}_{\mathrm{L}}=5.1\right.$, depth around $\left.270 \mathrm{~km}\right)$. The data recorded by E-PERM detectors, related to the whole seismic crisis, show that radon degassing at Stromboli is strongly influenced by structural discontinuities represented by the two major NE trending faults (see fig. 1a) and the complex geometry of the hydrothermal system [5]. Few days before and during the development of the seismic crisis (fig. 3a) drastic increases in radon emission were concentrated in the station just $\mathrm{NE}$ of the crater 


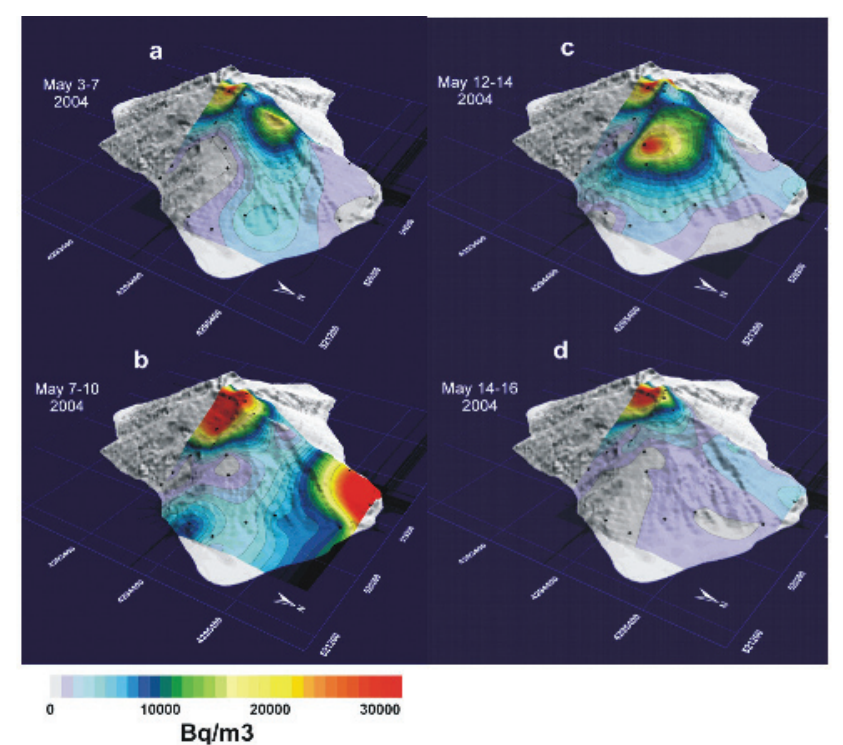

Figure 3: Sequence of ${ }^{222} \mathrm{Rn}$ emission before, during and after the Salina seismic event of May 5, 2004.

area, along the "main direction of dyking and fracturing". For two days after the seismic events (from May 7 to May 10) anomalies were recorded in the whole crater area and along the NE Sciara scarp and reached higher concentration at station 2 (see fig. 3b-c). After May 14 the highest radon emission was localised, as it usually happens, at the summit crater area. In fig. 4 is reported the temporal sequence of the measured radon emission at the summit sites that occurred before, during and after the "Salina" seismic event of May 5, 2004.

The analysis of the maps shown in fig. 3 suggests that once each of the stations has degassed and shown higher $\mathrm{Rn}$ anomalies, radon emission drops to its local background values. This behaviour is observed throughout the mapped area. The monitoring of the Salina seismic event shows that the response of the volcanic edifice, in terms of radon degassing, occurred rapidly, whereas degassing processes were effective for longer times and throughout the development of whole seimic crisis (including aftershocks, see ref. [8]).

\section{Conclusions}

Periodic radon surveys performed by means of a network of 21 stations at Stromboli Island allowed us to recognize the sites where diffuse degassing 


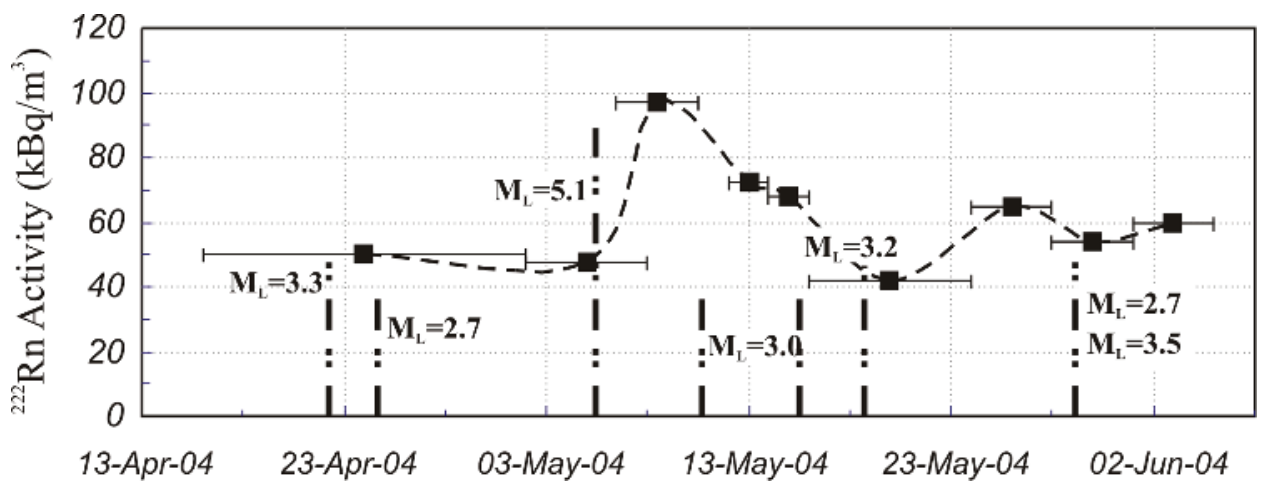

Figure 4: Radon emission at Summit sites (see fig. 1) are compared with seismic foreshocks and aftershocks in the area surrounding Salina during their seismic crisis (see text for details). Horizontal and vertical bars represent the "error bars" regarding the exposure time and the $2 \sigma$ uncertainties on the E-PERM ${ }^{\circledR}$ measurements, respectively.

from soil is more efficient. Higher average radon values have been observed in proximity of the main structural features of the islands (NE trending faults and Sciara del Fuoco scarp) and in the summit area nearby the active vents. Radon measurements during the last two major eruptive cycles that occurred at Stromboli volcano confirm a cause-effect relationship between changes in volcanic activity and variations in in-soil radon emission. Moreover, radon anomalies have been monitored during the development of the Salina seismic crisis. In this case, the dynamic response of the volcanic edifice, in terms of radon degassing, seems to be slightly delayed in time with respect to the seismic perturbations. In this view, continuous radon monitoring by using a network of automatic stations is a valuable tool to investigate the spatial and temporal variations of both diffuse degassing [9] and fluid motion along faults and fracture zones and its relationship with near-field seismicity.

\section{References}

[1] Bonetti R., Capra L., Chiesa C., Guglielmetti A. and Migliorini C., Nucl. Rad. Measur., 18 (1991) 321-338.

[2] Burton M.R., Caltabiano T., Murè F., Salerno G. and Randazzo D., J. Volcanol. Geotherm. Res., 182 (2009) 214-220.

[3] Planicić J., Radolić V. and Vuković B., Nucl. Instrum. Methods Phys. Res. A 530 (2004) 568-574. 
[4] Cox M.E., Cuff K.E. and Thomas D.M., Nature, 288 (1980) 74-76, doi: 10.1038/288074a0.

[5] Cigolini C., Gervino G., Bonetti R., Conte F., Laiolo M., Coppola D. and Manzoni A., Geophys. Res. Lett. 32 (2005) L12308, doi:10.1029/ 2005 GL022606.

[6] Cigolini C., Salierno G., Gervino G., Bergese P., Marino C., Russo M., Prati P., Ariola V., Bonetti R. and Begnini S., Geophys. Res. Lett. 28 (2001) 4035-4039.

[7] Gervino G., Cigolini C., Lavagno A., Marino C., Prati P., Pruiti L. and Zangari G., Physica A 340 (2004) 402-409.

[8] Cigolini C., Laiolo M. and Coppola D., Earth Planet. Sci. Lett. 257 (2007) 511-525.

[9] Cigolini C., Poggi P., Ripepe M., Laiolo M., Ciamberlini C., Delle Donne D., Ulivieri G., Coppola D., Lacanna G., Marchetti E., Piscopo D. and Genco R., J. Volcanol. Geotherm. Res. 184 (2009) 381-388. 